\title{
The Antecedents and Consequences of Fear at Work
}

\author{
Peter J. Jordan, Ashlea C. Troth, Neal M. Ashkanasy, and Ronald H. \\ Humphrey
}

Fear is the mind-killer.

\section{Frank Herbert, Dune (1965)}

Despite being identified as a pervasive emotion in the modern workplace (Pfeffer \& Sutton, 2000), fear oddly has not received a corresponding amount of attention among management researchers. In fact, Kish-Gephart, Detert, Treviño, and Edmondson (2009, p. 163) observe that we still have much to learn about the nature of fear in workplace settings, including "what it is, how and why it is experienced, and to what effects." Bennis (1966) notes further that fear has always been a part of the work environment (see also Connelly \& Turner, 2018), but it remains an especially important issue in today's workplaces because of the effects of rapid and ongoing organizational change, which are often linked to uncertain outcomes (Bordia, Hobman, Jones, Gallois, \& Callan, 2004; Tiedens \& Linton, 2001). Our aim in this chapter is to provide an overview of fear (arising from uncertainty) as a discrete emotion, to identify stimuli that may trigger fear at work, and to identify the potential positive and negative outcomes that can be linked to employees' fear. We also outline potential pathways for future research on fear of uncertainty in the workplace. 
It is not surprising to find that researchers have long studied fear in organizational contexts. Such studies have examined fear as a response to change (Bordia et al., 2004; Kiefer, 2005); during organizational failure (Vuori \& Quy, 2016); as a factor of organizational climate (Ashkanasy \& Nicholson, 2003); and during knowledge transfer (Empson, 2001). With respect to the effects of fear, researchers have examined its impact on coping strategies (Cheng, Kuan, Li, \& Ken, 2010); workplace violence (Budd, Arvey, \& Lawless, 1996); and decision-making (Li, Ashkanasy, \& Ahlstrom, 2014). While this research base is limited, it nonetheless provides a platform for gaining a greater understanding of fear and for exploring the broader implications of fear in today's changing and uncertain workplaces. Despite this beginning, however, much more work is required if we are to gain a broad understanding of fear of uncertainty at work. A starting point is to establish a clear construct definition for fear.

\section{What is Fear?}

Ekman (1992) broadly describes fear as a negatively valenced emotion that emerges in a range of intensities from mild nervousness, to anxiety, to full-blown fear and panic. There seem, however, to be disparate viewpoints regarding the triggers for fear. For example, Kish-Gephart et al. (2009) argue that fear usually results from an individual's perception of threat (see also LeDoux, 2013). Other authors propose that fear occurs in response to disruption (Hebb, 1946), to risk (Warr \& Stafford, 1983), to danger (Tamir, 2016), to ambiguity (Whalen, 1998), or to uncertainty (Solomon, 1993). More recently, Barrett (2006) argues for a homologous view of emotion suggesting that common emotions share common stimuli (e.g. irritation, annoyance, and anger have a common 
trigger of negative justice perceptions). Frijda (1987) and Lebel (2017) argue that fear at various levels of intensity emerges largely from a single common stimulus: perceptions of uncertain outcomes. Although we recognize that there are many sources of fear, including perceptions of threats, we focus specifically on fear as a response to employees' perceptions of uncertainty at work.

Thus, using Barrett's (2006) arguments - which seek to simplify the explanation of what stimuli create discrete emotions - we consider perceptions of uncertain outcomes as one important driver of fear in work settings. Indeed, each of the sources of fear we mentioned earlier (threat, disruption, risk and so on) can be seen to involve perceptions of uncertainty about outcomes. Moreover, Baumgartner, Pieters, and Bagozzi (2008) argue that fear is an example of an anticipatory emotion. In other words, fear is an actor's affective response to the prospect of a future event that has potential negative consequences for the individual. Thus, encapsulating this view, uncertainty about what is going to happen next contributes to fear.

Fear in response to perceptions of uncertainty is especially relevant in workplace settings, particularly during change (Bordia et al., 2004; Tiedens \& Linton, 2001). In this case, by gaining a better understanding of fear of uncertainty in the workplace, researchers may contribute to resolving the myriad difficult situations at work involving uncertain outcomes.

Although some researchers argue that uncertainty results in other discrete emotions such as hope (Fitzgerald, 2014) or anger (Fudenberg, Rand, \& Dreber, 2012), we contend that these reactions tend to be secondary appraisal reactions linked to coping mechanisms (cf. Lazarus \& Folkman, 1984). As such, they differ from fear, which constitutes a primary reaction to an uncertain outcome. Drawing on the stress and 
coping literature, we know that a secondary appraisal of uncertainty produces a cognitive process involving a consideration of the situation and the resources available to individuals to cope with that stressor (Biggs, Brough, \& Drummond, 2017). In other words, if individuals have sufficient resources and experience, they might see hope emerge from a situation involving uncertainty, or even reconsider the justice implications of the uncertainty and have an anger reaction. In line with Barrett's (2006) view of emotions, we argue that fear, in varying intensities, is a natural initial emotion (primary appraisal) experienced by any employees who encounter uncertainty.

A further issue to consider is that fear reactions emerge in a range of intensities from mild concern through nervousness to full-blown panic. Ekman (1992) outlines a framework for a family of discrete emotions (all which emerge at varying levels of intensity with different descriptors). Low-intensity emotions (e.g. nervousness, concern, or worry) all fall within the family of fear and, drawing on Barratt's (2006) arguments, a common stimulus should drive them. Similarly, we argue that, at the other end of the spectrum, high-intensity emotions (e.g. panic, terror, or fright) also fall within the family of fear and are responses to more intense uncertainty. We acknowledge, however, that these emotions are initial reactions that may be modified through secondary appraisal processes to morph into emotions such as anger, hope, or sadness at a later stage. In this chapter, however, we focus on fear as an initial emotional reaction to uncertainty in workplace settings.

\section{The Behavioral Outcomes of Fear}

The behavioral consequences of fear may be direct or indirect. On the one hand, the results of neuroscience research demonstrate that fear can directly result in 
conditioned responses (Ghosh \& Chattarji, 2015), which confirms early thoughts about fear (e.g. see Hebb, 1946) as being linked to automatic reactions. On the other hand, the results of social science research (see Baumeister, Vohs, DeWall, \& Zhang, 2007) suggest that emotions shape behavior indirectly, rather than directly. Specifically, Baumeister and colleagues argue that emotions contribute to cognitive processes that subsequently drive behavior.

In fact, closer examination of the neuroscientific data appears to show that both perspectives are correct. In this regard, LeDoux (2012a) found that, although emotional stimuli are processed across the cortex, hippocampus, and amygdala regions of the brain (i.e. they are cognitive processes), a shortcut route exists that facilitates a direct path from the sensory thalamus to the amygdala (a conditioned response) - without going through the cortex or the hippocampus. Gross and Canteras (2012) describe this as an evolutionary circuit. In view of this discovery, Lindebaum and Jordan (2014) argue that simplistic arguments that emotional stimuli are either direct or indirect processes ignore the complex networks that underpin this link. In acknowledging the complexity of these frameworks, moreover, it seems reasonable to conclude that fear can result in both automatic (direct) and considered (indirect) behaviors.

Studying these ideas in more detail, we see that automatic responses (Ghosh \& Chattarji, 2015) result in a single common reaction. In the case of fear, a fright may result in a jump reaction; or extreme danger may result in freezing (LeDoux, 2012b). Regarding automatic reactions to fear, research regarding the direct behavioral outcomes of fear emphasizes the startle effect, or an involuntary defensive reflex in response to sudden or unexpected stimuli (Valls-Solé, Kumru, \& Kofler, 2008). This research also shows that startle responses can vary in individuals from mild to extreme. 
Kolb (1991) identified in particular that individuals suffering from post-traumatic stress disorder are typically more reactively sensitive to fear (and have significantly heighted startle responses). In contrast, Ridgeway and Hare (1981) report a reduced startle response in individuals who engage in sensation-seeking behaviors (e.g. skydivers, adventurers). Finally, we note that a startle response relates to the intensity of the situation or the stimuli that precipitates the fear (Davis \& Wagner, 1969). At work, extreme forms of startle responses may be evident in events such as workplace industrial accidents or in the face of workplace violence. Researchers note that these conditioned responses can be moderated through therapy or training (Kashdan, Adams, Read, \& Hawk, 2012).

Alternatively, the inclusion of cognition (a delay in the response) in this process results in emotions indirectly shaping behavior (as suggested by Baumeister and his colleagues, 2015). On this basis, an experience of uncertain outcomes still creates an emotional response. However, where the individual is provided time to consider the potential outcomes (a cognitive process) they may have a range of different responses, with cognition partly determining the eventual behavior based on the personal resources available to that individual (e.g., skills, abilities, experience). In this process, reactions to fear have been most typically identified as fight/flight responses (Diest et al., 2001).

In terms of non-automatic responses, Carver (2006) notes the link between affective systems and behavioral systems. Looking at fear in an emotion regulation framework, we see that, once cognition is introduced to the process, there are significant individual differences in people's responses to fear (Zorawski, Cook, Kuhn, \& LaBar, 2005), as well as the emotion regulation strategies they adopt to manage fear 
(Hartley \& Phelps, 2010). We note here that fear is generally associated with avoidance behaviors (rigid and passive responses), or behavioral reactions associated with flight.

In terms of approach behaviors (fight-type reactions) linked to fear, Marsh, Ambady, and Kleck (2005) found that individuals who see others expressing fear are likely to engage in approach behaviors, just to understand what is happening. In this research, Marsh and her colleagues found that individuals respond faster to the target when observing target-expressed fear, rather than when observing anger; and that individuals are more likely to engage with a fearful person (whereas they seek to avoid angry people). This research supports other findings (Batson et al., 1997) demonstrating that individuals who correctly identify a fearful response are more likely to help the individual who expressed that fear. If this is so, then fear can result in approach behaviors from others who witness fear.

Fear can also result in proactive avoidance behaviors. Lebel (2017) notes that experienced fear may result in a proactive response designed to protect the individual from the stimuli that produced the fear. For example, an employee who learns that an organizational change is occurring may proactively approach a manager to find out information about the change so they can position themselves (with skills or knowledge) to respond to that change to their benefit. Lebel argues that emotion regulation (for instance, being appropriate and measured in the way you approach the manager) is a key part of that process. From a neuroscience perspective, Moscarello and Hartley (2017) argue that controllability is also a factor in determining whether fear results in proactivity. They found that, in specific uncertain situations where individuals feel they have some control (whether through experience or expertise), such individuals are more likely to take a proactive approach to attempt to resolve the 
uncertainty. For instance, if an employee is faced with a new task (e.g. a service agent who needs to deal with an angry customer's complaint), s/he may have less fear if s/he has control over the resources to solve that problem, or more fear if s/he lacks the decision-making authority to solve the problem. If the individual has little autonomy and constantly needs to refer the customer's complaint to others for a decision, s/he may expect the customer to have increasing anger at the inability to resolve the problem. This may result in the employee having greater fear and being less proactive.

So far, we have dealt with the factors leading to a perception of fear in the workplace, especially the role of perceived uncertainty and potential general reactions to fear. In the following section, we discuss in more particular detail the consequences of fear in the workplace occasioned by perceptions of uncertainty.

\section{Fear at Work}

There is clear evidence that we work in uncertain times. Indeed, our daily fears are constantly heightened by news reports ranging from terrorist attacks in workplaces (such as those in France and Australia: see Dilanian, 2019), to the threat of climate change (Gabbatiss, 2019), to threats to our way of life based on economic changes including uncertainty created by government reactions to increased levels of immigration (Reich, 2019).

A recent example of fear linked to significant events can be drawn from the entertainment industry. In an October 2017 edition of the New York Times, Kantor and Twohey (2017) reported that dozens of women had accused Harvey Weinstein, a Hollywood film producer, of sexual harassment spanning several decades. Notably, victims cited fear as the explanation for their silence, including physical fear, fear of 
missed job opportunities, fear of damaged reputations, and a fear of being disbelieved by others. Consequences for the victims included delayed career advancement as well as significant health issues, including post-traumatic stress disorder. For the organizations involved, it led to a tarnished image and major financial losses. The wave of publicity following the scandal highlights the prevalence of these types of incidents (and fear) across a range of industries and countries.

Another example of a workplace climate of fear (see also Ashkanasy \& Nicholson, 2003) can be found in the scandal at Volkswagen, whereby engineers admitted to cheating on US diesel emissions tests. Because of these admissions, Volkswagen's share price plummeted by 30 percent in three days and the company paid out $\$ 18$ billion in fines and lawsuits (English, 2015). According to the engineers, they engaged in the unethical behavior because of three factors: (1) pressure to meet unrealistic performance targets (fear of failure); (2) the context of Volkswagen's disorganized and uncoordinated compliance strategy; and (3) fears about how senior management would respond if they voiced their concerns (Hetzner, 2017).

In Australia, the "Dr. Death" scandal at Bundaberg Base Hospital resulting from the unskilled practices of Dr. Jayant Patel has similar features (fear-induced silence), and in this case horrifying outcomes: the death of patients (Edwards, Lawrence, \& Ashkanasy, 2016). All three cases described involve delayed reporting by employees caused specifically by fear, with the fear primarily caused by perceptions of uncertainty about the consequences of their whistleblowing. An especially disturbing aspect of TV and radio interviews with employees involved in all these cases is that interviewees stated that the fear-inducing events underpinning these incidents were not isolated; in fact, they are commonplace. 


\section{Everyday Work Events that Generate Fear}

Beyond these more dramatic examples, employees also experience everyday fear in relation to their jobs. While there are of course many uncertainty-causing situations at work, in this section we focus on three specific everyday events in the workplace:

(1) uncertainty created by work activity (what we do); (2) uncertainty caused by relationships at work, such as supervisor/subordinate relationships (who we work with); and (3) uncertainty caused by change (what may happen in the future). We consider these generally to typify situations in which uncertain outcomes can emerge at work, and that these may create a fear reaction of varying intensity.

\section{Fear Resulting from Uncertainty about What We Do}

Leach et al. (2013) note two broad sources of work activity uncertainty: (1) resource uncertainty, and (2) task uncertainty.

Resource uncertainty, on the one hand, arises from the idea that the flow of resources (personnel, time, funding) that employees have available to them may be uncertain at times and often cannot be accurately predicted. For instance, a job where there are competing demands may create resource uncertainty if we have limited time to complete the tasks. We note that a lack of clarity around the availability and distribution of resources can enhance employee uncertainty (Lambrechts, Demeulemeester, \& Herroelen, 2008) and this may result in a fear reaction such as nervousness or concern.

Task uncertainty, on the other hand, occurs when workers do not know what task their managers may be asking them to complete next, or how to do it. Parker 
(2014) argues, in particular, that task uncertainty is commonly experienced at work and suggests further that specific job designs can be beneficial in coping with uncertainty in the workplace. For example, employees working in customer service may have clear lines of responsibility and a set of specific tasks they are required to perform as a part of their role, while those working in less structured environments such as ad hoc project teams may not have this level of certainty in their day-to-day activities. In this regard, Cordery, Morrison, Wright, and Wall (2010) found that task uncertainty contributes to decreased team performance because employees need to find additional resources, such as time, to resolve uncertainty. In terms of additional resource required, this may include both emotional and cognitive coping resources required to deal with a fear-linked reaction.

\section{Fear Resulting from Uncertainty Caused by Relationships}

Kramer (2014) argues that the nature of interpersonal relationships at work automatically introduces a level of uncertainty at work. Uncertainty in relationships can emerge from the introduction of new employees through recruitment (Kramer, 1993); from clashes in working styles, as individuals struggle to understand those who may have different personal work style preferences (see Armstrong \& Priola, 2001), or who have different approaches to completing work (for instance, methodical versus ad hoc completion of tasks, or early versus late starters). All employees experience the nervousness associated with starting a new job or working in a new team (Appelbaum, Bregman, \& Moroz, 1998). There is also research evidence to suggest that supervisor/subordinate relationships can be uncertain, particularly where there is abusive supervision (Thau, Bennett, Mitchell, \& Marrs, 2009). The nature of 
relationships at work is such that one cannot guarantee another employee's motivations, priorities, or responses, and this, in and of itself, creates a perception of uncertainty which can lead to a fear-related reaction.

\section{Fear Resulting from Uncertainty Caused by Change}

As we noted earlier, Bordia et al. (2004) found that organizational change increases perception of uncertainty. This is especially acute in organizational change processes that adopt a flexible approach, where the speed, scope, and complexity of the change are often unpredictable (Leana \& Barry, 2000). Researchers note a link between change and fear reactions, as we are often unsure of potential losses that we may experience as a part of the change process (Moran \& Brightman, 2004). We also note that uncertainty caused by change is likely to lead to uncertainty about what we do (task uncertainty) and uncertainty about relationships (who we work with). We note that the three factors we identified as creating uncertainty may be closely linked, or at times even interdependent.

\section{Workplace Outcomes of Fear}

The question we now turn to is: what are the workplace outcomes from fear, especially fear occasioned by uncertainty? The small amount of research completed in this field has shown that fear at work has significant negative outcomes including contributing to workplace silence (Kish-Gephart et al., 2009), employees hiding bad news and lying to their bosses (Pfeffer \& Sutton, 2000), and reduced innovation (Bommer \& Jalajas, 1999). Pfeffer and Sutton argue further that fear leads employees to repeat past mistakes and to avoid seeking ways to improve the situation at hand. Lerner and 
colleagues (2015) note further that people experiencing fear, especially in uncertain environments, are more likely to be pessimistic in assessing future events, and tend to perceive more risk in decision-making tasks. Kline and Lewis (2018) note, in addition, that the outcomes of fear at work in response to bullying and harassment negatively affect employee health and result in costs through sickness, employee turnover, reduced productivity, and increased legal proceedings (to resolve disputes between employees and between the organization and the employee).

Finally, and contrary to the foregoing line of argument, we note the evidence that some people are actually able to deal with fear and anxiety and even thrive in this context (e.g. emergency service workers). For instance, Frye and Wearing (2016) discuss the use of metacognition (actively thinking about how we learn from experiences to direct future behavior; see Moshman, 2018) by firefighters to reduce uncertainty and fear during bushfires. As Desmond (2011) notes, firefighters do not lack fear, but they instead feel that their expertise can introduce a level of personal control that enables them to walk into fires. Examining another of the emergency services, policing, Verhage, Noppe, Feys, and Ledegen, (2018) found that fear and stress are a normal part of a police officer's experiences in the field and that many decisions are made while experiencing fear. The training of police now incorporates a range of psychological tools to assist their decision making while experiencing fear (Verhag et al., 2018). Based on these examples, clearly fear may be managed with the right level of self-awareness and training. 


\section{Fear as a Motivator?}

Having made the case so far in this chapter that the effects of fear can be destructive, we would be remiss if we did not also acknowledge that, under the right circumstances, fear can act as a positive motivator. We are not advocating a "carrot and stick" management approach (Andreoni, Harbaugh, \& Vesterlund, 2003). Rather taking the view that a fight response to fear involves defensive reactivity (Schauer \& Elbert, 2010), responses to fear can result in motivation for individuals to address that fear. In this regard, Clarke (2005) describes how uncertainty and fear can often be used to help employees to support drastic measures required to ensure a company's long-term viability. For instance, employees at Honeywell were asked to take unpaid furlough in 2009 to allow the company to avoid layoffs during a troubled economic time (Cote, 2013). Although this was not a pleasant experience for employees, in this case the organization used fear to ensure continued employment - especially when the alternative is the entire workforce losing their jobs.

Another example of a motivating use of fear occurred in a hospital setting where medical staff attempted (successfully) to reduce cross-infection rates through regular handwashing. Helder et al., (2012) described the introduction of screensavers on the hospital's computers that showed infectious germs multiplying exponentially every time an employee used a computer. This action increased employee uncertainty in relation to the cleanliness of surfaces in the hospital. Because of this intervention, hand hygiene compliance increased in the hospital from 58 percent to 98 percent. In this case, the intention was not to elicit high-intensity fear but rather to create uncertainty, and therefore lower-intensity concern (or fear), about the cleanliness of surfaces. 


\section{Future Directions for Fear Research in the Workplace}

Our first suggestion for future research arises from Gooty, Gavin, and Ashkanasy's

(2009) point that researchers need to do more research into the antecedents and effects of discrete emotions in the workplace. Gooty and colleagues specifically note the emotion of fear as fruitful grounds for more attention. A primary goal of any such research program should be to understand what triggers fear at work. We have already argued that fear emerges in response to workplace events characterized by uncertain outcomes. We also noted that fear can emerge in different intensities. On this basis, we see value in understanding relationships between the type or nature of the uncertainty and the intensity of fear experienced. In this instance, the question arises: can the difference in fear experienced by employees vary between activities? For example, is dealing with customers a more intense experience compared with dealing with colleagues? Also, do individual differences (confidence, self-esteem, locus of control, tolerance for ambiguity) moderate this relationship?

There is also a need to identify effective interventions to assist people who must constantly deal with uncertain outcomes and the subsequent fears associated with those outcomes (Jordan \& Lindebaum, 2015). While Gibbs, Drummond, and Lachenmeyer (1993) address this issue in the case of emergency service workers who face extreme situations, the question arises as to whether interventions can be developed to assist other workers such as call centre operators or customer service officers who face uncertainty daily in their interactions with customers and who deal with fear that may be linked to those events. For instance, both interpersonal skills 
training (to cope with unpredictable clients) and problem-solving training (to reduce uncertainty by providing problem-solving techniques) may work in these instances.

Research is also needed to study the efficacy of training in resilience, emotional intelligence, and emotion regulation in responding to fear at work (e.g. Nelis, Quoidbach, Mikolajczak, \& Hansenne, 2009; Troth et al., 2018). Such training clearly has potential to assist individuals in managing their reactions to fear at work. If Lebel's (2017) arguments are correct about fear leading to proactivity, then research could determine if there are ways in which employees can be trained to see fear as a positive motivator rather than a negative influence.

Another useful avenue to explore is the application of Geddes and Callister's (2007) dual threshold model to study how employees react fearfully to uncertainty. In fact, Geddes and Callister have already applied their model to study anger in the workplace, and found that too little anger results in apathy, while too much (which they describe as being beyond the appropriateness threshold for the expression of anger) is also not productive. Our question in relation to fear is whether there is a similar curvilinear relationship between fear and performance (in line with the framework proposed by Yerkes and Dodson, 1908). Recently, Lindebaum and Jordan (2012) argued that the dual threshold model can be broadened into a framework for understanding the effects of other discrete emotions. If our earlier arguments are correct - that, under the right conditions, fear can be a motivator - then understanding the intensity of uncertainty required to achieve this reaction would constitute an important contribution to the management field. 


\section{Conclusion}

Fear is an important evolutionary emotion (LeDoux, 2012b). It evolved as a basic reaction in human beings. Encouraging employees not to display fear at work means that important signals will not be received about uncertain outcomes at work, and how (effectively or not) that uncertainty is being managed. Our review implies that fear is an important part of organizational life and a part of the processes that keep employees active and responsive in addressing uncertainty in the work environment. Given that uncertainty is increasing in organizations, we argue that fear is a signal that a situation is not clear. As such, researchers would do well to look in more depth at the behavioral outcomes of uncertainty-generated fear at work, not just for individual employees but also at multiple levels of the organization.

chapter-references

\section{References}

Andreoni, J., Harbaugh, W., \& Vesterlund, L. (2003). The carrot or the stick: Rewards, punishments, and cooperation. American Economic Review, 93, 893-902.

Appelbaum, S. H., Bregman, M., \& Moroz, P. (1998). Fear as a strategy: Effects and impact within the organization. Journal of European Industrial Training, 22, 113127.

Armstrong, S. J., \& Priola, V. (2001). Individual differences in cognitive style and their effects on task and social orientations of self-managed work teams. Small Group Research, 32, 283-312. 
Ashkanasy, N. M., \& Nicholson, G. J. (2003). Climate of fear in organisational settings: Construct definition, measurement and a test of theory. Australian Journal of Psychology, 55, 24-29.

Barrett, L. F. (2006). Solving the emotion paradox: Categorization and the experience of emotion. Personality and Social Psychology Review, 10, 20-46.

Batson, C. D., Sager, K., Garst, E., Kang, M., Rubchinsky, K., \& Dawson, K. (1997). Is empathy-induced helping due to self-other merging? Journal of Personality and Social Psychology, 73, 495-509.

Baumeister, R. F., Vohs, K. D., DeWall, C. N., \& Zhang, L. (2007). How emotion shapes behavior: Feedback, anticipation, and reflection, rather than direct causation. Personality and Social Psychology Review, 11, 167-203.

Baumgartner, H., Pieters, R., \& Bagozzi, R. P. (2008). Future-oriented emotions:

Conceptualization and behavioral effects. European Journal of Social Psychology, $38,685-696$.

Bennis, W. G. (1966). Changing organizations. Journal of Applied Behavioral Science, 2, 247-263.

Biggs, A., Brough, P., \& Drummond, S. (2017). Lazarus and Folkman's psychological stress and coping theory. In C. L. Cooper \& J. C. Quick (Eds.), The handbook of stress and health: A guide to research and practice (pp. 349-364). Chichester, UK: Wiley.

Bommer, M., \& Jalajas, D. (1999).The threat of organizational downsizing on the innovative propensity of R\&D professionals. R\&D Management, 29, 27-34. 
Bordia, P., Hobman, E., Jones, E., Gallois, C., \& Callan, V. J. (2004). Uncertainty during organizational change: Types, consequences, and management strategies. Journal of Business and Psychology, 18, 507-532.

Budd, J. W., Arvey, R. D., \& Lawless, P. (1996). Correlates and consequences of workplace violence. Journal of Occupational Health Psychology, 1, 197-210.

Carver, C. S. (2006). Approach, avoidance, and the self-regulation of affect and action. Motivation and Emotion, 30, 105-110.

Cheng, Y. H., Kuan, F. Y., Li, C. I., \& Ken, Y. (2010). A comparison between the effect of emotional certainty and uncertainty on coping strategies. Social Behavior and Personality, 38, 53-60.

Clarke, M. (2005). The voluntary redundancy option: Carrot or stick? British Journal of Management, 16, 245-251.

Connelly, S., \& Turner, M. R. (2018). Functional and dysfunctional fear at work: dual perspectives. In D. Lindebaum, D. Geddes, \& P. J. Jordan (Eds.), Social functions of emotion and talking about emotion at work. Cheltenham, UK: Edward Elgar.

Cordery, J. L., Morrison, D., Wright, B. M., \& Wall, T. D. (2010). The impact of autonomy and task uncertainty on team performance: A longitudinal field study. Journal of Organizational Behavior, 31, 240-258.

Cote, D. (2013). Honeywell's CEO on how he avoided layoffs. Harvard Business Review, June, https://hbr.org/2013/06/honeywells-ceo-on-how-he-avoided-layoffs

Davis, M., \& Wagner, A. R. (1969). Habituation of startle response under incremental sequence of stimulus intensities. Journal of Comparative and Physiological Psychology, 67, 486-492. 
Desmond, M. (2011). Making firefighters deployable. Qualitative Sociology, 34, 59-77. Diest, I., Winters, W., Devriese, S., Vercamst, E., Han, J. N., Woestijne, K. P., \& Bergh, 0. (2001). Hyperventilation beyond fight/flight: respiratory responses during emotional imagery. Psychophysiology, 38, 961-968.

Dilanian, K. (2019). Report: Nearly all terror attacks in France carried out by radicals already known to police. $N B C$ News, 7 January, www.nbcnews.com/news/world/report-nearly-all-terror-attacks-francecarried-out-radicals-already-n955276

Edwards, M. S., Lawrence, S. A., \& Ashkanasy, N. M. (2016). Factors encouraging employee silence in response to wrongdoing: The case of Bundaberg Hospital. In N. M. Ashkanasy, C. E. J. Härtel, \& W. J. Zerbe (Eds.) Research on emotion in organizations (Volume 12, pp. 343-382). Bingley, UK: Emerald.

Ekman, P. (1992). An argument for basic emotions. Cognition \& Emotion, 6, 169-200.

Empson, L. (2001). Fear of exploitation and fear of contamination: Impediments to knowledge transfer in mergers between professional service firms. Human Relations, 54(7), 839-862.

English, A. (2015). VW scandal: “Culture of fear," The Telegraph Cars, 16 October, www.telegraph.co.uk/cars/volkswagen/news/emissions-scandal-culture-offear-led-to-dependence-on-diesel/

Fitzgerald, D. (2014). The trouble with brain imaging: Hope, uncertainty and ambivalence in the neuroscience of autism. BioSocieties, 9, 241-261.

Frijda, N. H. (1987). Emotion, cognitive structure, and action tendency. Cognition and Emotion, 1(2), 115-143. 
Frye, L. M., \& Wearing, A. J. (2016). A model of metacognition for bushfire fighters. Cognition, Technology \& Work, 18(3), 613-619.

Fudenberg, D., Rand, D. G., \& Dreber, A. (2012). Slow to anger and fast to forgive: Cooperation in an uncertain world. American Economic Review, 102, 720-749.

Gabbatiss, J. (2019). Climate change is creating toxic crops and poisoning some of world's poorest people, scientists warn. The Independent, 16 March, www.independent.co.uk/environment/climate-change-poison-crops-toxic-fungiethiopia-un-environment-a8823071.html

Geddes, D., \& Callister, R. R. (2007). Crossing the line(s): A dual threshold model of anger in organizations. Academy of Management Review, 32, 721-746.

Ghosh, S., \& Chattarji, S. (2015). Neuronal encoding of the switch from specific to generalized fear. Nature Neuroscience, 18, 112-120.

Gibbs, M. S., Drummond, J., \& Lachenmeyer, J. R. (1993). Effects of disaster on emergency workers: A review, with implications for training and post disaster interventions. Journal of Social Behaviour and Personality, 8, 189-212.

Gooty, J., Gavin, M., \& Ashkanasy, N. M. (2009). Emotions research in OB: The challenges that lie ahead. Journal of Organizational Behavior, 30, 833-838.

Gross, C. T., \& Canteras, N. S. (2012). The many paths to fear. Nature Reviews Neuroscience, 13, 651-659.

Hartley, C. A., \& Phelps, E. A. (2010). Changing fear: The neurocircuitry of emotion regulation. Neuropsychopharmacology, 35, 136-146.

Hebb, D. 0. (1946). On the nature of fear. Psychological Review, 53, 259-275. 
Helder, O. K., Weggelaar, A. M., Waarsenburg, D. C., Looman, C. W., van Goudoever, J. B., Brug, J., \& Kornelisse, R. F. (2012). Computer screen saver hand hygiene information curbs a negative trend in hand hygiene behavior. American Journal of Infection Control, 40, 951-954.

Herbert, F. (1965). Dune. Philadelphia, PA: Chiltern Books.

Hetzner, C. (2017). VW reforms compliance system to avoid another scandal. Automotive News Europe, 11 December, http://europe.autonews.com/article/20171211/ANE/171129801/vw-reformscompliance-system-to-avoid-another-scandal

Jordan, P. J., \& Lindebaum, D. (2015). A model of within person variation in leadership: Emotion regulation and scripts as predictors of situationally appropriate leadership. Leadership Quarterly, 26, 594-605.

Kantor, J., \& Twohey, M. (2017). Harvey Weinstein paid off sexual harassment accusers for decades. New York Times, 5 October, www.nytimes.com/2017/10/05/us/harvey-weinstein-harassmentallegations.html

Kashdan, T. B., Adams, L., Read, J., \& Hawk, L., Jr. (2012). Can a one-hour session of exposure treatment modulate startle response and reduce spider fears? Psychiatry Research, 196, 79-82.

Kiefer, T. (2005). Feeling bad: Antecedents and consequences of negative emotions in ongoing change. Journal of Organizational Behavior, 26, 875-897.

Kish-Gephart, J. J., Detert, J. R., Treviño, L. K., \& Edmondson, A. C. (2009). Silenced by fear: The nature, sources, and consequences of fear at work. In B. M. Staw \& L. L. 
Cummings (Eds.), Research in organizational behavior (Volume 29, pp. 163193). Oxford, UK: Elsevier Science.

Kline, R., \& Lewis, D. (2019). The price of fear: estimating the financial cost of bullying and harassment to the NHS in England. Public Money \& Management, 39, 166174.

Kolb, L. C. (1991). PTSD: Psychopathology and the startle response. Psychiatric Quarterly, 62, 233-250.

Kramer, M. W. (1993). Communication and uncertainty reduction during job transfers: Leaving and joining processes. Communications Monographs, 60, 178-198.

Kramer, M. W. (2014). Managing uncertainty in organizational communication. Mahwah, NJ: Routledge.

Lambrechts, O., Demeulemeester, E., \& Herroelen, W. (2008). Proactive and reactive strategies for resource-constrained project scheduling with uncertain resource availabilities. Journal of Scheduling, 11, 121-136.

Lazarus, R. S., \& Folkman, S. (1984). Stress, appraisal and coping. New York, NY: Springer.

Leach, D., Hagger-Johnson, G., Doerner, N., Wall, T., Turner, N., Dawson, J., \& Grote, G. (2013). Developing a measure of work uncertainty. Journal of Occupational and Organizational Psychology, 86, 85-99.

Leana, C. R., \& Barry, B. (2000). Stability and change as simultaneous experiences in organizational life. Academy of Management Review, 25, 753-759. 
Lebel, R. D. (2017). Moving beyond fight and flight: A contingent model of how the emotional regulation of anger and fear sparks proactivity. Academy of Management Review, 42, 190-206.

LeDoux, J. (2012a). Rethinking the emotional brain. Neuron, 73, 653-676.

LeDoux, J. E. (2012b). Evolution of human emotion: A view through fear. Progress in Brain Research, 195, 431-442.

LeDoux, J. E. (2013). The slippery slope of fear. Trends in Cognitive Sciences, 17, 155156.

Lerner, J. S., Li, Y., Valdesolo, P., \& Kassam, K. S. (2015). Emotion and decision making. Annual Review of Psychology, 66, 799-823.

Li, Y., Ashkanasy, N. M., and Ahlstrom, D. (2010). Complexity theory and affect structure: A dynamic approach to modeling emotional changes in organizations. In W. J. Zerbe, C. E. J. Härtel, \& N. M. Ashkanasy (Eds.), Research on emotion in organizations (Volume 6, pp. 139-165). Bingley, UK: Emerald.

Lindebaum, D., \& Jordan, P. J. (2012). Positive emotions, negative emotions, or utility of discrete emotions? Journal of Organizational Behavior, 33, 1027-1030.

Lindebaum, D., \& Jordan, P. J. (2014). A critique on neuroscientific methodologies in organizational behavior and management studies. Journal of Organizational Behavior, 35, 898-908.

Marsh, A. A., Ambady, N., \& Kleck, R. E. (2005). The effects of fear and anger facial expressions on approach-and avoidance-related behaviors. Emotion, 5, 119-124. 
Moran, J. W., \& Brightman, B. K. (2000). Leading organizational change. Journal of Workplace Learning, 12, 66-74.

Moscarello, J. M., \& Hartley, C. A. (2017). Agency and the calibration of motivated behavior. Trends in Cognitive Sciences, 21, 725-735.

Moshman, D. (2018). Metacognitive theories revisited. Educational Psychology Review, 30, 599-606.

Nelis, D., Quoidbach, J., Mikolajczak, M., \& Hansenne, M. (2009). Increasing emotional intelligence: (How) is it possible? Personality and Individual Differences, 47, 3641.

Parker, S. K. (2014). Beyond motivation: Job and work design for development, health, ambidexterity, and more. Annual Review of Psychology, 65, 661-691.

Pfeffer, J., \& Sutton, R. I. (2000). The knowing-doing gap: How smart companies turn knowledge into action. Boston, MA: Harvard Business Press.

Reich, R. (2019). Trump is cornered, with violence on his mind. We must be on red alert. The Guardian, 16 March, www.theguardian.com/usnews/commentisfree/2019/mar/16/donald-trump-breitbart-interview-whitesupremacy

Ridgeway, D., \& Hare, R. D. (1981). Sensation seeking and psychophysiological responses to auditory stimulation. Psychophysiology, 18, 613-618.

Schauer, M., \& Elbert, T. (2010). Dissociation following traumatic stress. Zeitschrift für Psychologie/Journal of Psychology, 218, 109-127. 
Solomon, R. C. (1993). The passions: Emotions and the meaning of life. Indianapolis, IN: Hackett.

Tamir, M. (2016). Why do people regulate their emotions? A taxonomy of motives in emotion regulation. Personality and Social Psychology Review, 20, 199-222.

Thau, S., Bennett, R. J., Mitchell, M. S., \& Marrs, M. B. (2009). How management style moderates the relationship between abusive supervision and workplace deviance: An uncertainty management theory perspective. Organizational Behavior and Human Decision Processes, 108, 79-92.

Tiedens, L. Z., \& Linton, S. (2001). Judgment under emotional certainty and uncertainty: The effects of specific emotions on information processing. Journal of Personality and Social Psychology, 81, 973-988.

Troth, A. C., Lawrence, S. A., Jordan, P. J., \& Ashkanasy, N. M. (2018). Interpersonal emotion regulation in the workplace: A conceptual and operational review and future research agenda. International Journal of Management Reviews, 20, 523543.

Valls-Solé, J., Kumru, H., \& Kofler, M. (2008). Interaction between startle and voluntary reactions in humans. Experimental Brain Research, 187, 497-507.

Verhage, A., Noppe, J., Feys, Y., \& Ledegen, E. (2018). Force, stress, and decision-making within the Belgian police: The impact of stressful situations on police decisionmaking. Journal of Police and Criminal Psychology, 33, 345-357.

Vuori, T. O., \& Huy, Q. N. (2016). Distributed attention and shared emotions in the innovation process: How Nokia lost the smartphone battle. Administrative Science Quarterly, 61, 9-51. 
Warr, M., \& Stafford, M. (1983). Fear of victimization: A look at the proximate causes.

Social Forces, 61, 1033-1043.

Whalen, P. J. (1998). Fear, vigilance and ambiguity: Initial neuroimaging studies of the human amygdala. Current Directions in Psychological Science, 7, 177-188.

Yerkes, R. M., \& Dodson, J. D. (1908). The relation of strength of stimulus to rapidity of habit-formation. Journal of Comparative and Neurological Psychology, 18, 459482.

Zorawski, M., Cook, C. A., Kuhn, C. M., \& LaBar, K. S. (2005). Sex, stress, and fear: Individual differences in conditioned learning. Cognitive, Affective, \& Behavioral Neuroscience, 5, 191-201. 